\title{
Validação de métodos laboratoriais aplicadas a análises com marcadores microssatélites ${ }^{1}$
}

\author{
Validation of laboratory methods applied to microsatellite markers
}

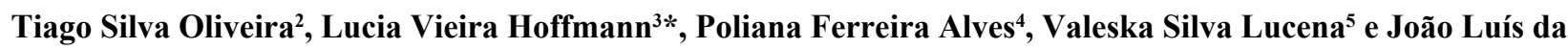 \\ Silva Filho ${ }^{6}$
}

\begin{abstract}
Resumo - A troca de informação sobre biodiversidade e a utilização de recursos genéticos podem ser melhor realizadas se os laboratórios que geram as informações puderem demonstrar que seus resultados são confiáveis através de metodologias adequadas de validação. Para definir critérios que sirvam para demonstrar a confiabilidade de resultados em laboratórios onde são realizadas pesquisas com marcadores de DNA, foram analisados erros associados à quantificação de DNA em gel de agarose e à repetitividade e robustez da reação da polimerase em cadeia (PCR) utilizando primers baseados em marcadores microssatélites (SSR). O erro associado à quantificação de DNA foi menor quando $100 \mathrm{ng}$ foram quantificadas, e aumentou para quantidades de DNA maiores, com a tendência de subestimar sua quantidade. O limite de quantificação, entendido como as menores diferenças de quantidade de DNA que o método detecta, variou expressivamente com pequena variação da quantidade de DNA. A incerteza associada ao PCR foi estimada por sua repetitividade, que mostrou-se sensível à quantidade de DNA da reação. A baixa robustez da PCR quanto à quantidade de DNA demonstra a necessidade prioritária de avaliação deste parâmetro. As considerações feitas podem ser auxiliares para que laboratórios de marcadores moleculares utilizem procedimentos de validação.
\end{abstract}

Palavras-chave - Genética Vegetal. Microssatélites. Laboratórios biológicos - controle de qualidade.

\begin{abstract}
Biodiversity information exchange and the use of genetic resources can be improved if the laboratories are able to assure their results thought suitable methodologies of validation. Aiming to define criteria which demonstrate the reliability of results in laboratories which work with DNA markers, errors associated to the DNA quantification in agarose gel, PCR repeatability and robustness using microsatellite (SSR) markers were analyzed. The error associated to DNA quantification was smaller when $100 \mathrm{ng}$ of DNA were quantified, and increased for greater amounts of DNA, tending to sub estimations. Quantification limits, or the smallest quantity detected by the method used, varied markedly with small variations on the DNA amounts. Uncertainty associated to microsatellite PCR reaction was measured by its repeatability, which was affected by the quantities of DNA in the reaction. The low robustness of the microsatellite PCR reaction due to sensibility to quantities of DNA showed the priority on evaluating this parameter. The presented methodologies may be useful to laboratories working with molecular markers implementing validation procedures.
\end{abstract}

Key words - Plant Genetics. Microsatellites. Biological laboratories - quality control.

\footnotetext{
* Autor para correspondência

${ }^{1}$ Recebido para publicação em 16/06/2009; aprovado em 22/04/2010

Pesquisa financiada pela Embrapa

${ }^{2}$ Curso de Ciências Biológicas, Universidade Estadual da Paraíba, Campina Grande-PB, Brasil, tsoliveira@gmail.com

${ }^{3}$ Embrapa Algodão - Núcleo do Cerrado, Rodovia GO-462, km 12, Zona Rural, Caixa Postal 179, Santo Antônio de Goiás-Goiás, Brasil, 75.375-000,

luciahoff@pq.cnpq.br

${ }^{4}$ Curso de Estatística, Universidade Estadual da Paraíba, Campina Grande-PB, Brasil, polianafalves@yahoo.com.br

${ }_{5}^{5}$ Departamento de Biologia, Universidade Estadual da Paraíba, Campina Grande-PB, Brasil, valeskasl@hotmail.com

${ }^{6}$ Embrapa Algodão, Campina Grande-PB, Brasil, joaoluis@cnpa.embrapa.br
} 


\section{Introdução}

Marcadores microssatélites, também conhecidos como sequências simples repetidas, ou simple sequence repeats (SSR), são uma ferramenta adequada e importante em genética de plantas, por serem abundantes e uniformemente distribuídos por todo genoma, codominantes e multialélicos (OLIVEIRA et al., 2006; OLIVEIRA E SILVA, 2008). Têm sido utilizados para estudar diversidade de populações naturais (BARROSO et al., 2010; BRONDANI et al., 2005) e de espécies cultivadas (ALMEIDA et al., 2009; ALVES et al., 2009; CRESTE et al., 2004), além de mapeamento molecular.

É importante que os laboratórios possam demonstrar que seus resultados são confiáveis, garantindo a repetitividade de testes por meio da validação de metodologias. Compilações ou regulamentações das metodologias aplicáveis têm sido pioneiramente desenvolvidas para organismos transgênicos (CRAIG et al., 2008), e podem ser aplicáveis para estudos de diversidade. Para isto, faz-se necessário o treinamento de pessoas que iniciam os trabalhos em laboratórios, uma vez que pode haver variações individuais na execução dos trabalhos, que podem ou não ser solucionadas pelo treinamento.

A validação de metodologias desenvolvidas em laboratórios é efetuada após seleção, desenvolvimento e otimização dos métodos (SWARTZ; KRULL, 1997), sendo destacada pelas normas internacionais, nacionais e sistema de qualidade, como um procedimento importante para a obtenção de resultados confiáveis ao uso pretendido.

Segundo INMETRO (2003), as características de desempenho investigadas no processo de validação, a fim de demonstrar o desempenho do método são: especificidade; exatidão; precisão; limite de detecção; limite de quantificação; linearidade; faixa de aplicação e robustez.

Com o objetivo de definir critérios que sirvam para demonstrar a confiabilidade de resultados em laboratórios onde se trabalha com marcadores de DNA, foram realizados pequenos experimentos que permitam uma diagnose dos erros associados às metodologias utilizadas para gerar marcadores microssatélites. O erro relacionado à quantificação de DNA por comparação com quantidades padrão, em gel de agarose, foi relacionado à robustez da reação em cadeia da polimerase. Estimaram-se também os erros associados às estimativas do tamanho de DNA em eletroforese em poliacrilamida.

\section{Material e métodos}

Para extração de DNA de sementes, a quantidade aproximada de $50 \mathrm{mg}$ de sementes de algodoeiros foram moídas em tubos de 2,0 $\mathrm{mL}$ contendo uma esfera de $3 \mathrm{~mm}$ de diâmetro. Adicionou-se $700 \mu \mathrm{L}$ de tampão de extração composto por SDS $0,5 \%$ (p/v), $288 \mathrm{mM}$ deNaCl, $25 \mathrm{mM}$ de EDTA, $200 \mathrm{mM}$ de Tris $\mathrm{HCl}(\mathrm{pH} \mathrm{7,5)}$. As amostras foram centrifugadas a $11.700 \mathrm{~g}$ por 7 minutos e os sobrenadantes foram transferidos para tubos novos. A cada suspensão foi adicionado $10 \mu \mathrm{L}$ de proteinase $\mathrm{K}\left(10 \mathrm{ng} \mathrm{mL}^{-1}\right)$ e $10 \mu \mathrm{L}$ de $1 \mathrm{mM} \mathrm{CaCl}_{2}$, que então foram incubadas em banho-maria a $37^{\circ} \mathrm{C}$ por 30 minutos e em seguida adicionado $500 \mu \mathrm{L}$ de isopropanol a $-20^{\circ} \mathrm{C}$. A seguir, centrifugou-se a $11.700 \mathrm{~g}$ por 10 minutos. O DNA precipitado foi lavado com $500 \mu \mathrm{L}$ de álcool a 70\%, duas vezes, e uma com álcool absoluto, em seguida, resuspenso em $300 \mu \mathrm{L}$ de tampão T. E. (TrisHCl $100 \mathrm{mM}$ pH 8; EDTA $5 \mathrm{mM}$ ).

Para extração de DNA de folhas, foram coletadas amostras de 50 a $100 \mathrm{mg}$ de folhas jovens de algodoeiros, e procedeu-se basicamente da mesma maneira que Menezes et al. (2008). O tecido foliar foi colocado em microtubos de capacidade de $1,5 \mathrm{~mL}$ e submergidas em nitrogênio líquido. A maceração foi feita com pistilos adaptados aos microtubos, na presença de nitrogênio líquido. Adicionou-se $600 \mu \mathrm{L}$ de tampão de extração (CTAB 2\% (m/v); $\mathrm{NaCl}$ 1,4 M; EDTA 0,2 M; Tris-HCl 0,1 M; pH 8; PVP 40 2\% (m/v) e 2-mercaptoetanol 0,2\% (v/v)). A suspensão foi incubada, em banho-maria, a $65{ }^{\circ} \mathrm{C}$ por 30 minutos e emulsionada, por inversão do microtubo, 10 vezes, com $600 \mu \mathrm{L}$ de clorofórmio e álcool isoamílico (24:1), as amostras foram centrifugadas a $11.700 \mathrm{~g}$ por 5 minutos a uma temperatura de $4{ }^{\circ} \mathrm{C}$. À fase aquosa foi adicionado $600 \mu \mathrm{L}$ de isopropanol gelado, e a mistura centrifugada a $11.700 \mathrm{~g}$ por 5 minutos. O DNA precipitado foi lavado duas vezes, sendo a primeira com álcool $70 \%(\mathrm{v} / \mathrm{v})$ e a segunda com álcool absoluto, e resuspenso em tampão T.E.

Para quantificação, o DNA foi aplicado em gel de agarose a $0,8 \%$ em tampão TBE (Tris-HC 89 mM; EDTA $2 \mathrm{mM}$; ácido bórico $89 \mathrm{mM})$, utilizando como controle quantidades conhecidas do fago $\lambda(50 ; 100 ; 200$ e 300 ng). $\mathrm{O}$ gel foi submetido à eletroforese por $1 \mathrm{~h} 30 \mathrm{~min}$ a 150 V, e então corado com Sybr green (ZIPPER, 2004). As quantidades de $100 ; 150 ; 200$ e $250 \mathrm{ng}$ de DNA foliar de $G$. barbadense foram estimadas por 5 diferentes avaliadores a partir da comparação com os padrões. Então, foram utilizadas para calcular o intervalo em que se espera que estejam 95\% das estimativas, para cada valor real, dadas pelos limites superior e inferior calculados pelo intervalo de confiança, com 5\% de significância, o desvio padrão de todas as amostras, a média e o erro da média.

A repetitividade das reações de PCR utilizadas para obtenção de marcadores microssatélites foram avaliadas pela amplificação de 50 repetições do mesmo DNA genômico, dos genótipos de algodoeiro herbáceo (Gossypium hirsutum) da variedade Guazuncho-2 e do algodoeiro G. barbadense VH8-4602, com os primers CIR140; 141; 143; 148; 203 e 212 (Nguyen et al., 2004). As reações foram realizadas 
conforme Menezes et al. (2008). Após cada reação foram adicionados $10 \mu \mathrm{L}$ de azul de bromofenol, e os fragmentos de DNA produzidos foram separados em gel de desnaturante de poliacrilamida a 6\% (acrilamida: bisacrilamida 19:1), e uréia 7M. As bandas foram coradas por nitrato de prata (CRESTE et al., 2001).

A robustez da reação de PCR (INMETRO, 2003) foi avaliada utilizando-se diferentes quantidades de DNA (de 3 a 5 ng) nas reações.

A adequação de modelos de regressão utilizados para o cálculo do número de pares de bases de moléculas de DNA foi feita em eletroforese de géis de poliacrilamida. Mediram-se as bandas fornecidas por um marcador de peso molecular de $50 ; 100 ; 150 ; 200 ; 250 ; 300$ e 350 , em milímetros, em 3 diferentes cubas, com 6 repetições para cada cuba. Os valores foram utilizados para cálculo do número de pares de base de acordo com dois diferentes métodos: i) um modelo de regressão em que o tamanho do DNA, em número de pares de base, é igual ao inverso da mobilidade, em milímetros (SURZYCKI, 2000). ii) Um modelo de regressão de melhor ajuste escolhido pelo programa Table Curve 2D (STACON, 2010). Os limites superior e inferior de erro esperado para cada tamanho de molécula foram estimados pelo intervalo de confiança, com $5 \%$ de significância.

\section{Resultados e discussão}

\section{Quantificação de DNA}

A comparação entre as quantidades estimadas de DNA por 5 diferentes avaliadores, e seus valores reais, estão apresentados na Tabela 1. Para este ensaio, foi extraído DNA de sementes de algodão de um genótipo de Gossypium barbadense, cultivar VH8-4602 (McDONALD et al., 1994).

A Tabela 1 mostra que o valor real de 100 ng de DNA foi estimado 35 vezes sendo $60 \%$ de acertos. O uso de DNA de apenas um genótipo, com um pequeno número de repetições, visa servir como um exemplo de dados a serem submetidos ao mesmo tipo de análise. Entende-se que embora seja difícil definir parâmetros de validação para metodologias que são variáveis entre laboratórios e que constantemente são modificadas buscando-se melhorias (SHAH et al., 2000), pode ser útil documentar dados obtidos para possibilitar ou facilitar o desenvolvimento e uniformização destes métodos.

A porcentagem de acerto caiu com o aumento da quantidade de DNA, sendo 40; 57 e 20\%, respectivamente, para 150; 200 e 250 ng de DNA. Assim, para diminuir os erros associados à quantificação de DNA pode-se sugerir
Tabela 1 - Valores de frequência e porcentagem obtidos pela comparação entre as quantidades estimadas a partir dos fragmentos de DNA foliar de algodoeiro e os valores reais

\begin{tabular}{|c|c|c|c|}
\hline $\begin{array}{l}\text { Real } \\
(\mathrm{ng})^{*}\end{array}$ & $\begin{array}{c}\text { Estimada } \\
(\mathrm{ng})^{*}\end{array}$ & $\begin{array}{l}\text { Frequência } \\
\text { da quantidade } \\
\text { estimada }\end{array}$ & $\begin{array}{l}\text { Porcentagem } \\
\text { da quantidade } \\
\text { estimada }\end{array}$ \\
\hline \multirow{7}{*}{100} & 200 & 1 & 3 \\
\hline & 150 & 1 & 3 \\
\hline & 100 & 21 & 60 \\
\hline & 90 & 1 & 3 \\
\hline & 75 & 4 & 11 \\
\hline & 70 & 4 & 11 \\
\hline & 50 & 3 & 9 \\
\hline Total & & 35 & \\
\hline \multirow{4}{*}{150} & 200 & 8 & 27 \\
\hline & 180 & 1 & 3 \\
\hline & 150 & 12 & 40 \\
\hline & 100 & 9 & 30 \\
\hline Total & & 30 & \\
\hline \multirow{6}{*}{200} & 300 & 15 & 19 \\
\hline & 250 & 3 & 4 \\
\hline & 200 & 46 & 57 \\
\hline & 170 & 2 & 2 \\
\hline & 150 & 7 & 9 \\
\hline & 100 & 7 & 9 \\
\hline Total & & 80 & \\
\hline \multirow{3}{*}{250} & 200 & 2 & 40 \\
\hline & 250 & 1 & 20 \\
\hline & 300 & 2 & 40 \\
\hline Total & & 5 & \\
\hline
\end{tabular}

a repetição da quantificação do DNA quando este for quantificado como maior que $100 \mathrm{ng}$.

Nota-se também, pela observação da Tabela 1, que mais raramente estimaram-se as quantidades de DNA como maiores que as reais; e estimativas que subestimam a quantidade de DNA levam a colocar-se na reação uma quantidade maior que a prevista.

$\mathrm{O}$ intervalo em que se espera que estejam $95 \%$ das estimativas das quantidades de DNA, para cada valor real, estão apresentados na Tabela 2. Supondo que o erro aqui calculado mantenha-se ao longo das análises no mesmo laboratório, pode ser usado como uma medida de incerteza das análises desse laboratório. Assim, o intervalo 
de confiança nos permite afirmar que se espera que o valor real de $100 \mathrm{ng}$ de DNA seja estimado entre 85 e $102 \mathrm{ng}$, em $95 \%$ das estimativas. Segundo o mesmo raciocínio, o valor real de $150 \mathrm{ng}$ seja estimado entre 135 e $163 \mathrm{ng}$; e o valor $200 \mathrm{ng}$, entre 150 e $219 \mathrm{ng}$, com a mesma significância. Novas medidas de incerteza, estimadas com o mesmo procedimento, podem ser tomadas posteriormente, pois é possível que um treinamento continuado dos avaliadores, ou percepção e correção de erros sistemáticos, as medidas de incerteza caiam ao longo do tempo.

A quantidade de $100 \mathrm{ng}$ de DNA pôde ser diferenciada da quantidade de $150 \mathrm{ng}$ em 33 das 35 avaliações, exceto uma vez que foi quantificada como 150 ng e outra como 200 ng (Tabela 1). Entretanto, também pela Tabela 1 , o valor de $150 \mathrm{ng}$ foi em $27 \%$ das estimativas confundido com $200 \mathrm{ng}$. O sucesso da quantificação usando o método de comparação em gel de agarose depende do limite de quantificação (LOQ) alcançado pela amostra que corresponde à menor diferença entre quantidades de DNA que podem ser detectadas pelo método de quantificação (INMETRO, 2003). Uma proposta possível é de que os valores sejam suficientemente distantes para que os limites superiores e inferiores, nos quais se agrupam $95 \%$ das estimativas, não se sobreponham, como mostram os dados apresentados na Tabela 2.

Nota-se que $100 \mathrm{ng}$ de DNA são facilmente diferenciados de $150 \mathrm{ng}$, já que o limite superior para $100 \mathrm{ng}$ $(102,36)$ está longe do limite inferior para $150 \mathrm{ng}(135,49)$.
Considerando apenas esta faixa de variação, o limite de quantificação é inferior a $50 \mathrm{ng}$. Entretanto, no caso do valor real de $150 \mathrm{ng}$, o limite inferior de $200 \mathrm{ng}(149,59)$ é menor que o limite superior de $150 \mathrm{ng}(163,17)$. Sendo assim, o limite de quantificação é maior que $50 \mathrm{ng}$ e menor que $100 \mathrm{ng}$. Nota-se também, que neste pequeno número de dados, usado como exemplo, pode haver aumento de erro estimado causado pelo pequeno número de amostras utilizado para as maiores quantidades de DNA.

\section{Repetitividade da reação de PCR e robustez}

A mensuração da repetitividade do método da amplificação de DNA por primers que amplificam locos microssatélites, estimada pela intensidade das bandas obtidas a partir da amplificação de 50 reações utilizando DNAs extraídos de sementes dos algodoeiros, G. hirsutum variedade Guanzuncho-2 e Gossypium barbadense variedade VH8-4602, em reações independentes, está apresentada na Tabela 3.

Apenas 2 oligonucleotídeos (CIR143 e CIR203) amplificaram e apresentaram $100 \%$ de repetitividade das bandas. $\mathrm{O}$ uso do mesmo DNA com diferentes primers mostrou que há fatores intrínsecos aos primers que influenciam na repetitividade. A nitidez considerada ruim não impede a análise de bandas, mas, quando possível, selecionam-se aqueles de melhor nitidez. A repetitividade é uma boa medida de incerteza em análises qualitativas (ELLISON et al., 1998), e pôde auxiliar na seleção de primers.

Tabela 2 - Resultados dos valores de quantificação estimados por 5 observadores das 30 amostras de DNA de G. barbadense com os respectivos dados estatísticos: média, desvio padrão, erro padrão médio e intervalo de confiança estimados para cada valor real

\begin{tabular}{cccccc}
\hline $\begin{array}{c}\text { Valor real de } \\
\text { DNA (ng*) }\end{array}$ & Média & Desvio padrão & $\begin{array}{c}\text { Erro padrão } \\
\text { médio }\end{array}$ & Limite inferior & Limite superior \\
\hline 100 & 93,43 & 26,95 & 4,55 & 84,5 & 102,36 \\
150 & 149,33 & 38,68 & 7,06 & 135,49 & 163,17 \\
200 & 205,75 & 55,48 & 6,2 & 149,59 & 218,9 \\
\hline
\end{tabular}

*nanogramas

Tabela 3 - Frequência de bandas de boa nitidez, ou fracas ou ausentes, em 50 repetições com o mesmo DNA, de acordo com o primer utilizado

\begin{tabular}{ccccccccc}
\hline & & \multicolumn{1}{c}{ Locos } \\
\cline { 2 - 9 } & & CIR140 & CIR143 & CIR148 & CIR203 $\mathrm{h}^{*}$ & CIR203 b* & CIR212 \\
\hline \multirow{3}{*}{ Nitidez } & Boa & 46,6 & 100 & 53,33 & 100 & 98 & 70 \\
\cline { 2 - 9 } & ruim & 23,33 & 0 & 46,67 & 0 & 0 & 16,67 \\
\cline { 2 - 9 } & ausente & 30 & 0 & 0 & 0 & 2 & 13,33 \\
\hline
\end{tabular}

*As letras h e b referem-se aos resultados para DNA extraído de G. hirsutum e G. barbadense, respectivamente 
A avaliação para saber se o erro de quantificação de DNA é aceitável depende do conhecimento da robustez do método de PCR quanto a esse parâmetro. Isto é, se o erro de 100 ng na quantificação do DNA, para mais ou para menos, não implicar em perda de eficiência da reação de PCR, este limite de quantificação é aceitável. A robustez de um método de ensaio mede a sensibilidade que este apresenta em face de pequenas variações (INMETRO, 2003). A PCR deve ser robusta em relação a variações na quantidade de DNA, pois, a quantificação pode apresentar erros. Além disso, os DNAs são distribuídos individualmente, enquanto outros componentes da PCR são previamente misturados, constituindo um único mix, onde eventuais erros estarão igualmente distribuídos por todas as amostras.

Em reações com volume final de 13 a $15 \mu \mathrm{L}$, utilizando-se $3 \mathrm{ng}$ de DNA genômico, 65\% a 87,3\% de 63 indivíduos de uma população F2 derivada do cruzamento de G. hirsutum variedade Guanzuncho2 e Gossypium barbadense variedade VH8-4602, apresentaram bandas nítidas. Quando a reação foi preparada da mesma maneira, mas utilizaram-se 4 ng de DNA, esse valor foi de $65 \%$ a $100 \%$ de bandas nítidas. Com a quantidade de $5 \mathrm{ng}$ de DNA, 90,48\% a $100 \%$ apresentaram bandas nítidas. Portanto, o erro na quantificação de DNA apresenta uma relação direta com a eficiência do PCR. Além disso, embora exista uma quantidade ótima de DNA na reação (5 ng) para a melhor eficiência, uma quantidade menor de DNA ( $3 \mathrm{ng}$ ) permite a leitura dos resultados em boa parte das amostras (65\%).

\section{Tamanho de alelos}

As estimativas do número de pares de bases de cada banda do marcador de peso molecular após a análise de regressão de melhor ajuste, para cada caso, fornecida pelo programa TableCurve 2, estão apresentadas na Tabela 4 .

Como pode-se observar na Tabela 4, os limites inferior e superior, que agrupam 95\% das estimativas, desviaram-se de 0 e 3 pares de base do valor verdadeiro, tendendo para valores menores. Para algumas combinações entre cubas e tamanhos dos fragmentos de DNA, os valores reais são menores que o limite inferior ou maiores que o limite superior, sugerindo a necessidade de se estabelecer um modelo de regressão. Entretanto, a utilização do modelo em que o número de pares de base é igual ao inverso da mobilidade, em milímetros (SURZYCKI, 2000) gerou limites superiores e inferiores mais distantes do que os valores reais (dados não apresentados). Embora no experimento tenha-se procurado manter constantes as principais condições que influenciam a mobilidade eletroforética do DNA (viscosidade da solução; voltagem; distância entre os pólos), o uso de um modelo de regressão pré-estabelecido não foi auxiliar. Assim, se as variações são grandes, o melhor modelo que permite o ajuste da curva de regressão é variável. Neste caso, a medição correta do número de pares de base em géis de poliacrilamida só é alcançada com a utilização de DNAs controles, que amplificam um fragmento de tamanho conhecido. O tamanho do fragmento, disponível na literatura ou em dados públicos para os laboratórios participantes da análise, deve ser utilizado para conferência do tamanho estimado. Caso

Tabela 4 - Estimativas do número de pares de bases de fragmentos de DNA de tamanhos reais de 50 a 350 pb, em diferentes cubas

\begin{tabular}{ccccccccc}
\hline & & \multicolumn{7}{c}{ Tamanhos reais } \\
\cline { 3 - 8 } & & 50 & 100 & 150 & 200 & 250 & 300 & 350 \\
\hline \multirow{3}{*}{ Cuba 1 } & Média & 50,89 & 98,90 & 149,20 & 200,05 & 251,93 & 299,94 & 349,06 \\
& Limite superior & 51,18 & 99,30 & 149,51 & 200,78 & 253,64 & 303,70 & 350,55 \\
& Limite inferior & 50,59 & 98,51 & 148,88 & 199,32 & 250,21 & 296,17 & 347,58 \\
\hline \multirow{3}{*}{ Cuba 2 } & Média & 50,62 & 97,60 & 147,61 & 198,06 & 249,56 & 300,48 & 346,24 \\
& Limite superior & 51,87 & 99,59 & 150,28 & 201,24 & 252,96 & 304,12 & 349,45 \\
& Limite inferior & 49,37 & 95,62 & 144,95 & 194,88 & 246,15 & 296,84 & 343,03 \\
\hline \multirow{3}{*}{ Cuba 3 } & Média & 52,01 & 98,46 & 148,8 & 200,35 & 252,59 & 299,98 & 349,37 \\
& Limite superior & 53,68 & 99,02 & 149,16 & 201,68 & 255,55 & 304,87 & 352,33 \\
& Limite inferior & 50,33 & 97,89 & 148,44 & 199,02 & 249,63 & 295,09 & 346,41 \\
\hline \multirow{2}{*}{ Total } & Média & 51,17 & 98,32 & 148,54 & 199,49 & 251,36 & 300,13 & 348,22 \\
& Limite superior & 51,89 & 99,03 & 149,44 & 200,69 & 252,99 & 302,38 & 349,82 \\
& Limite inferior & 50,45 & 97,61 & 147,63 & 198,28 & 249,72 & 297,89 & 346,63 \\
\hline
\end{tabular}


haja inconsistência, toda a análise do tamanho dos fragmentos, desde a confecção do gel, deve ser repetida.

\section{Conclusões}

1. A precisão da quantificação de DNA varia com a quantidade de DNA mensurada.

2. A reação de PCR para obtenção de marcadores microssatélites é altamente sensível à quantidade de DNA, que deve ser o principal parâmetro a ser considerado em medições de robustez.

\section{Referências}

Almeida, V.C.etal. In situ and genetic characterization of Gossypium barbadense L. from the States of Pará and Amapá, Brazil. Pesquisa Agropecuária Brasileira, v. 44, n. 07, p. 719-725, 2009.

ALVES, M. F. et al. Marcadores moleculares polimórficos entre algodoeiros mocós e herbáceos. Revista Ciência Agronômica, v. 40, n. 03, p. 406-411, 2009.

Barroso, P. A. V. et al. In situ conservation and genetic diversity of three populations of Gossypium mustelinum Miers (ex Watt). Genetic Resources and Crop Evolution, v. 57, n. 03, p. 343349, 2010.

BRONDANI, R. P. V. et al. Genetic structure of wild rice Oryza glumaepatula populations in three Brazilian biomes using microsatellite markers. Genetica, v. 125, p. 115-123, 2005.

CRESTE, S.; TULMANN NETO, A.; FIGUEIRA, A. Detection of single sequence repeat polymorphisms in denaturing polyacrylamide sequencing gels by silver staining. Plant Molecular Biology Reporter, v. 19, n. 04, p. 299-306, 2001.

CRAIG, W. et al. An overview of general features of risk assessments of genetically modified crops. Euphytica, v. 164, n. 03, p. 853-880, 2008.

CRESTE, S. et al. Genetic diversity of Musa and triploid accessions from the Brazilian banana breeding program estimated by microsatellite markers. Genetic Resources and Crop Evolution, v. 51, n. 07, p. 723-733, 2004.
ELLISON, S. L. R.; GREGORY, S.; HARDCASTLE, W. A. Quantifying uncertainty in qualitative analysis. The Analyst, v. 123, p. 1155-1161, 1998.

INSTITUTO NACIONAL DE METROLOGIA E NORMALIZAÇÃO E QUALIDADE INDUSTRIAL (INMETRO). Orientações sobre validação de métodos de ensaios químicos. 2003. 35 p.

McDONALD, M. D.; ELLIOT, L. J.; SWEENEY, P. A. DNA extraction from dry seeds for RAPD analyses in varietal identification studies. Seed Science and Technology, v. 22, n. 01, p. 171-176, 1994.

MENEZES, I. P. P. et al. Distância genética entre linhagens avançadas de germoplasma de algodão com uso de marcadores de RAPD e microssatélites. Pesquisa agropecuária Brasileira, v. 43, n. 10, p. 1339-1347, 2008.

NGUYEN, T. B. et al. Wide coverage of the tetraploid cotton genome using newly developed microsatellites markers. Theoretical and Applied Genetics, v. 109, n. 01, p. 167-175, 2004.

OLIVEIRA, E. J. et al. Origin, evolution and genome distribution of microsatellites. Genetics and Molecular Biology, v. 29, n. 02, p. 294-307, 2006.

OLIVEIRA, M. S. P.; SILVA, K. J. D. Diferenciação genética entre procedências de açaizeiro por marcadores moleculares RAPD e SSR. Revista Brasileira de Fruticultura, v. 30, n. 02, p. $438-443,2008$

Shah, V. P. et al. Bioanalytical method validation - A revisit with a decade of progress. Pharmaceutical Research, v. 17, n. 12 , p. 1551-1557, 2000

STATISTITICAL CONSULTING AND SOFTWARE (STATCON). Table curve 2d.2010@. Disponível em: $<$ HTTP:// www.statcon.de/statconshop/producthttp:info.htm?products $\mathrm{id}=1 \&$ language $=\mathrm{en}>$. Acesso em: 5 mar. 2010 .

SURZYCKI, S. Basic techniques in molecular biology. New York: Springer-Verlag, 2000. 448 p.

SWARTZ, M.; KRULL, I. Analytical method development. New York: Marcel Dekker, 1997. 96 p.

ZIPPER, H. et al. Investigations on DNA intercalation and surface binding by SYBR Green I, its structure determination and methodological implications. Nucleic Acids Research, v. 32, n. 12 , p. 294-299, 2004 